\title{
Impact of exercise training on the sarcopenia criteria in non-alcoholic fatty liver disease: a systematic review and meta-analysis
}

\author{
Andrea Gonzalez (1,2,3), Mayalen Valero-Breton (1,2,3), Camila Huerta-Salgado \\ $(1,2,3)$, Oscar Achiardi (4), Felipe Simon $(2,5,6)$, Claudio Cabello-Verrugio $(1,2,3)$
}

(1) Laboratory of Muscle Pathology, Fragility and Aging, Department of Biological Sciences, Faculty of Life Sciences. Universidad Andres Bello, Santiago, Chile; (2) Millennium Institute on Immunology and Immunotherapy, Santiago, Chile; (3) Center for the Development of Nanoscience and Nanotechnology (CEDENNA), Universidad de Santiago de Chile, Santiago, Chile; (4) Escuela de Kinesiología, Facultad de Ciencias, Pontificia Universidad Católica de Valparaíso, Valparaíso, Chile; (5) Millennium Nucleus of Ion Channel-Associated Diseases (MiNICAD), Universidad de Chile, Santiago, Chile; (6) Laboratory of Integrative Physiopathology, Department of Biological Sciences, Faculty of Life Sciences. Universidad Andres Bello, Santiago, Chile.

This article is distributed under the terms of the Creative Commons Attribution Noncommercial License (CC BY-NC 4.0), which permits any noncommercial use, distribution, and reproduction in any medium, provided the original author(s) and source are credited.

\begin{abstract}
Sarcopenia is a highly prevalent complication of non-alcoholic fatty liver disease (NAFLD). We aimed to conduct a systematic review and meta-analyses to elucidate the exercise training (ET)'s efficacy on NAFLD adult patients' sarcopenia criteria. We identified relevant randomized controlled trials (RCT) in electronic databases PubMed, CINAHL, and Scopus. We selected seven RCT from 66 screened studies. The ET programs included endurance or combined (endurance and resistance) training. No study performed resistance training alone. The physical function improved with endurance or combined training (mean differences [MD] 8.26 $\mathrm{mL} / \mathrm{Kg}$ *min [95\% CI 5.27 to $11.24 \mathrm{~mL} / \mathrm{Kg} * \mathrm{~min}$ ], $\mathrm{p}<0.0001$ ); Muscle mass showed no evidence of the beneficial effects of endurance or combined training (MD 1.01 Kg [95\% CI -1.78 to 3.80 $\mathrm{Kg}], \mathrm{p}=0.48)$. None of the selected studies evaluated muscle strength. Endurance and combined training increase physical function criteria but do not improve muscle mass criteria on sarcopenia in NAFLD patients. These results must be interpreted with caution for the small number of patients included in the RCTs analyzed, the different characteristics of the ET carried out, the non-use of resistance training, which prevents assess its effect on sarcopenia despite the evidence that recommends it and does not assessment muscle strength criteria in RCT include. Future research should include muscle strength assessments and resistance training to evaluate the effects in this condition. Exercise training is beneficial for sarcopenia in NAFLD but is necessary more experimental evidence to define the best type of training that positively affects the three criteria of sarcopenia. PROSPERO reference number CRD42020191471.
\end{abstract}

Key Words: endurance training, resistance training, sarcopenia, non-alcoholic fatty liver disease, skeletal muscle.

Non-alcoholic fatty liver disease (NAFLD) is the most common chronic liver disease (CLD). It includes a broad spectrum of disorders ranging from accumulating lipids in the liver (steatosis) to the progressive inflammation denoted as non-alcoholic steatohepatitis (NASH) to advanced stages of damage such as fibrosis and cirrhosis., ${ }^{1,2}$

Sarcopenia is one of the most common complications associated with NAFLD, with $30-70 \%$ prevalence. $^{3}$ According to the European Working Group on Sarcopenia in Older People (EWGSOP), sarcopenia diagnosis is based on three criteria: i) low muscle strength (the primary indicator of sarcopenia), ii) small muscle quantity or quality, and iii) low physical performance. ${ }^{4}$ Sarcopenia negatively affects NAFLD progression; ${ }^{5}$ its severity is more pronounced in the advanced stages of NAFLD, considered an independent predictor of pre- and post-liver transplant complications and mortality. ${ }^{6,7}$ Therefore, therapeutic interventions to prevent, revert or improve sarcopenia associated with NAFLD are essential.

Since sarcopenia involves a decline in muscle mass, strength, and physical performance, exercise training 
(ET) is a promising tool for treating sarcopenia. ${ }^{8}$ Due to low-quality evidence, the results of studies that evaluate the effect of ET on patients with cirrhosis-associated sarcopenia are highly variable and inconclusive. ${ }^{9}$ Despite proof that training has a positive impact on liver dysfunction parameters in patients with NAFLD, ${ }^{10,11}$ no studies evaluate the effect of training on sarcopenia criteria in NAFLD patients. Besides, to prevent functional decline, it is critical to establish the best exercise type to improve muscle strength, muscle mass, and physical performance in NAFLD patients. Thus, more evidence is required to determine exercise specifications (type, intensity, frequency, supervised vs. domiciliary). ${ }^{1}$

Considering all the antecedents, the effects of ET on sarcopenia criteria associated with NAFLD are not determined. Therefore, our objective was to conduct a systematic review and meta-analyses to elucidate the exercise training's efficacy on strength, muscle mass, and physical performance in adult patients with NAFLD.

\section{Methods}

\section{Protocol and Registration}

We conducted our systematic review and meta-analysis following the Preferred Reporting Items for Systematic Reviews and Meta-Analysis (PRISMA) statement (See $\mathrm{S} 1)$. We registered the review protocol in the International Prospective Register of Systematic Reviews (PROSPERO reference number CRD42020191471), available from 3 September 2020.

\section{Search strategy}

We performed a systematic search in PubMed, CINAHL, and Scopus from March-May 2020. We included articles published from January 2000-March 2020 containing the critical concepts of sarcopenia, fatty liver disease, exercise, and related words. The essential concepts of the search were different for each database. For example, for PubMed, we used the keywords ('atrophic muscular disorders' OR 'muscle atrophy' OR 'muscle degeneration' OR 'muscle fiber atrophy' OR 'muscle fiber degeneration' OR ‘muscle wasting' OR ‘muscular wasting' OR 'muscular atrophy' OR 'muscular atrophies’ OR ‘muscular degeneration' OR ‘sarcopenia’) AND ('non-alcoholic steatosis' OR 'non-alcoholic fatty liver disease' OR 'fatty liver' OR 'hepatic fat' OR 'liver fibrosis' OR 'liver disease' OR 'fatty liver disease’ OR 'obesity') AND ('exercise' OR 'physical activity' OR 'exercise intervention' OR 'training') (See S2). We filtered the results for clinical randomized controlled trials (RCTs). Then, AG reviewed all titles and abstracts from the articles selected and only downloaded those matching the inclusion criteria.

\section{Inclusion/exclusion criteria}

Inclusion and exclusion criteria are listed in Table 1. Two researchers ( $\mathrm{CH}-\mathrm{S}$ and $\mathrm{MV}-\mathrm{B})$ independently reviewed the full-text version of the reports. They resolved
Table 1. Inclusion and exclusion criteria

\section{Inclusion criteria}

- The inclusion criteria are based on the study population, intervention, comparison question (control), and outcomes (PICO). ${ }^{12}$

- Investigate adults (18 or older) with liver disease of non-alcoholic origin (expressly, NAFLD or NASH) as confirmed by at least one of these parameters: hepatic biopsy, ultrasonography, computed tomography (CT), nuclear magnetic resonance spectroscopy (MRS), serum bile acids, gammaglutamyl transpeptidase (GGT), aminotransferases, the ratio of aspartate transaminase (AST)/alanine transaminase (ALT) or bilirubin, alkaline phosphatase, dyslipidemia) (Population). ${ }^{13-17}$

- Apply resistance training, endurance training, or both. Combined exercise is defined as interventions that simultaneously used resistance and endurance training (Intervention).

- Apply exercise alone or in combination with other interventions (educational, nutritional, etc.); must have a control group and a group with exercise only (to determine its independent effect) (Control). Control groups cannot have any intervention that could influence study outcome measures (e.g., nutritional or physical intervention). Moreover, the exercise group participants must perform three or more training sessions per week for at least four weeks to determine the chronic effect of exercise on the variables. Studies must conduct pre- and postintervention assessments to identify changes in the variables.

- Assay sarcopenia criteria included in the consensus definition of sarcopenia: ${ }^{1,4}$ muscle strength, defined as the force generated through muscular contraction against an external load; ${ }^{18}$ muscle mass, defined as the part of total body mass composed of skeletal muscle tissue; ${ }^{19}$ and physical performance, defined as an objectively measured whole body function related with mobility. ${ }^{20}$ Thus, the studies must evaluate sarcopenia criteria, as was described in S3 (Outcome).

- Be a peer-reviewed study

- Be written only in English

\section{Exclusion criteria}

- Bibliographic reviews, not controlled or randomized clinical trials, animal models

- The participants had comorbidities: type II diabetes mellitus, viral hepatitis, cardiovascular disease, lung disease, or neurological disease.

- Interventions that would interfer with identifying any exercise-mediated effects. 
Exercise training in non-alcoholic fatty liver disease

Eur J Transl Myol 31 (1): 9630, 2021 doi: 10.4081/ejtm.2021.9630

Table 2. Included studies—exercise programming details and sarcopenia criteria's assessment

\begin{tabular}{|c|c|c|c|c|c|c|c|c|c|c|c|}
\hline & \multicolumn{2}{|c|}{$\mathbf{n}$} & \multicolumn{3}{|c|}{ Endurance training } & \multicolumn{3}{|c|}{ Resistance Training } & \multicolumn{3}{|c|}{$\begin{array}{c}\text { Sarcopenia criteria's } \\
\text { assessment }\end{array}$} \\
\hline Study & EX & CG & Duration & Intensity & Method & Duration & Intensity & Method & PP & MM & Strength \\
\hline $\begin{array}{l}\text { Sullivan } \\
(2012)^{21}\end{array}$ & 12 & 6 & $\begin{array}{l}30-60 \mathrm{~min} \\
5 \mathrm{x} / \mathrm{wk} \\
16 \mathrm{wk}\end{array}$ & $\begin{array}{l}45 \%-55 \% \\
\mathrm{VO}_{2 \text { peak }}\end{array}$ & Walking & NA & NA & NA & CPET & DXA & NA \\
\hline $\begin{array}{l}\text { Pugh } \\
(2013)^{22}\end{array}$ & 6 & 5 & $\begin{array}{l}\text { 30-45 min } \\
3-5 / w k \\
12-16 \text { wk }\end{array}$ & $\begin{array}{l}30 \%-60 \% \\
\text { HRR }\end{array}$ & Gymnasium & NA & NA & NA & CPET & NA & NA \\
\hline $\begin{array}{l}\text { Pugh } \\
(2014)^{23}\end{array}$ & 13 & 8 & $\begin{array}{l}30-45 \mathrm{~min} \\
3-5 \mathrm{x} / \mathrm{wk} \\
12 \mathrm{wk}\end{array}$ & $\begin{array}{l}30 \%-60 \% \\
\text { HHR }\end{array}$ & $\begin{array}{l}\text { Cycle } \\
\text { ergometer }\end{array}$ & NA & NA & NA & CPET & NA & NA \\
\hline $\begin{array}{l}\text { Shojaee- } \\
\text { Moradie } \\
(2016)^{24}\end{array}$ & 15 & 12 & $\begin{array}{l}20-60 \mathrm{~min} \\
4-5 \mathrm{x} / \mathrm{wk} \\
16 \mathrm{wk}\end{array}$ & $\begin{array}{l}40 \%-60 \% \\
\text { HRR }\end{array}$ & $\begin{array}{l}\text { Gymnasium } \\
\text { and outdoor } \\
\text { aerobic } \\
\text { activities }\end{array}$ & $\begin{array}{l}20-60 \mathrm{~min} \\
4-5 \mathrm{x} / \mathrm{wk} \\
16 \mathrm{wk}\end{array}$ & NR & NR & CPET & NA & NA \\
\hline $\begin{array}{l}\text { Hallsworth } \\
(2015)^{25}\end{array}$ & 11 & 12 & $\begin{array}{l}30-40 \\
\min \\
3 x / w k \\
12 w k\end{array}$ & $\begin{array}{l}\text { RPE 16- } \\
17\end{array}$ & $\begin{array}{l}\text { Cycle } \\
\text { ergometer }\end{array}$ & $\begin{array}{l}30-40 \\
\mathrm{~min} \\
3 \mathrm{x} / \mathrm{wk} \\
12 \mathrm{wk}\end{array}$ & $\begin{array}{l}\text { Light } \\
\text { band } \\
\text { resisted }\end{array}$ & $\begin{array}{l}\text { Face-pull, } \\
\text { horizontal } \\
\text { push, } \\
\text { horizontal } \\
\text { pull, and } \\
30^{\circ} \text { push. }\end{array}$ & СРET & $\mathrm{ADP}$ & NA \\
\hline $\begin{array}{l}\text { Houghton } \\
(2017)^{26}\end{array}$ & 12 & 12 & $\begin{array}{l}45-60 \mathrm{~min} \\
3 \mathrm{x} / \mathrm{wk} \\
12 \mathrm{wk}\end{array}$ & $\begin{array}{l}\text { RPE 16- } \\
18\end{array}$ & Cycling & $\begin{array}{l}45-60 \mathrm{~min} \\
3 \mathrm{x} / \mathrm{wk} \\
12 \mathrm{wk}\end{array}$ & $\begin{array}{ll}\text { RPE } & 14- \\
16 & \end{array}$ & $\begin{array}{l}\text { Knee } \\
\text { extension, } \\
\text { horizontal } \\
\text { row, chest } \\
\text { press, } \\
\text { vertical } \\
\text { row }\end{array}$ & CPET & $\mathrm{ADP}$ & NA \\
\hline $\begin{array}{l}\text { Cheng } \\
(2017)^{27}\end{array}$ & 29 & 29 & $\begin{array}{l}30-60 \text { min } \\
2-3 x / \text { wk } \\
6,8-11 \\
\text { months }\end{array}$ & $\begin{array}{l}60 \%-75 \% \\
\mathrm{VO}_{2 \max }\end{array}$ & $\begin{array}{l}\text { Nordic } \\
\text { brisk } \\
\text { walking }\end{array}$ & NA & NA & NA & $\begin{array}{l}2-\mathrm{Km} \\
\text { WT }\end{array}$ & DXA & NA \\
\hline
\end{tabular}

discrepancies/disagreements by consensus. When this was not possible, two independent researchers acted as referees (AG and CC-V).

\section{Data extraction}

We collected the data from seven final papers $(n=7)$, which we tabulated and ordered into a Microsoft Excel 2016 database. One researcher extracted the data, and two different researchers reviewed it to ensure data processing accuracy (Table 2). The data included the following parameters: first author's surname; publication year; the number of participants in a group; type, intensity, frequency, and duration of the exercise intervention; sarcopenia criteria assessment methods. When studies presented intention-to-treat (ITT) values, we only extracted ITT data. Data extraction and synthesis for the outcome of interest are shown in the data synthesis section.

\section{TESTEX rating scale application}

We assessed study quality using the TESTEX rating scale (Table 3). ${ }^{28}$ It includes criteria to evaluate methodological quality as well as ranking the whole article. The scale comprises 12 assessment criteria for a maximum score of 15 points. Higher ratings reflect better study quality and reporting. ${ }^{28}$ TESTEX does not yet provide a validated cut-off score, ${ }^{28}$ so we categorized the studies depending on the median score. ${ }^{10,29}$ We classified studies above the median score as 'high-quality' and those below as 'low-quality'. AG and OA performed TESTEX scoring separately. When different evaluations occurred, they discussed discrepancies until reaching a consensus score.

\section{Data synthesis}

When at least three included studies reported the same outcome, we pooled data to perform a meta-analysis using Review Manager 5.4 (RevMan 5.4) as per the Cochrane Manual for Systematic Reviews of Interventions. ${ }^{30}$ We used a random-effects model for heterogeneity to address study participants' different backgrounds and various exercise interventions (which create differences in training variables such as exercise intensity and duration, session frequency, etc.). Outcome measures also differ among studies depending on the available technology to quantify muscle mass and 


\begin{tabular}{|c|c|c|c|c|c|c|c|c|c|c|c|c|c|}
\hline \multicolumn{14}{|c|}{ Table 3 Study quality using the TESTEX rating scale. } \\
\hline StudylScore & 1 & 2 & 3 & 4 & 5 & 6 & 7 & 8 & 9 & 10 & 11 & 12 & TOTAL \\
\hline 2012 Sullivan $^{21}$ & 1 & 1 & 1 & 1 & 0 & 2 & 0 & 2 & 1 & 0 & 1 & 1 & 11 \\
\hline 2013 Pugh $^{22}$ & 1 & 0 & 1 & 1 & 0 & 3 & 0 & 2 & 1 & 0 & 1 & 1 & 11 \\
\hline 2014 Pugh $^{23}$ & 1 & 1 & 1 & 1 & 0 & 1 & 0 & 2 & 1 & 0 & 1 & 1 & 10 \\
\hline 2016 Shojaee-Moradie ${ }^{24}$ & 1 & 1 & 1 & 1 & 0 & 1 & 0 & 2 & 1 & 0 & 1 & 1 & 10 \\
\hline 2015 Hallsworth $^{25}$ & 1 & 1 & 1 & 1 & 0 & 0 & 0 & 2 & 1 & 0 & 1 & 1 & 9 \\
\hline 2017 Hughton $^{26}$ & 1 & 1 & 1 & 1 & 0 & 3 & 0 & 2 & 1 & 0 & 1 & 1 & 12 \\
\hline \multirow[t]{2}{*}{2017 Cheng $^{27}$} & 1 & 1 & 1 & 1 & 1 & 2 & 1 & 2 & 1 & 0 & 1 & 1 & 13 \\
\hline & & & & & & & & & & Median & 11 & & \\
\hline
\end{tabular}

physical performance. Finally, we expected methodological heterogeneity, as exercise training research uses different designs. We used inverse variance because we analyzed continuous data to compare exercise vs. control or conventional care groups using mean and standard deviations from post-intervention values for each outcome. When other forms of variability measures such as standard error or confidence intervals (CIs) appeared, we calculated the standard deviations using RevMan 5.4. ${ }^{30}$ We did not plan to investigate patients' subgroups, as we expected the participants to be homogeneous (see inclusion criteria). However, considering the heterogeneous nature of exercise training protocols, we expected to find different exercise training types classified as either endurance or resistance. In this variety, we planned to perform a subgroup analysis comparing endurance training vs. resistance training, investigate the heterogeneity across subgroup results, and analyze the variability in effect estimates between exercise types using an $\mathrm{I}^{2}$ statistic. For each outcome analyzed, we present the data as mean differences (MD) with a $95 \%$ CI. We used standardized mean differences (SMD) to represent effect sizes and facilitate interpretations, ${ }^{31}$ with a value of 0.2 set as small, 0.5 as
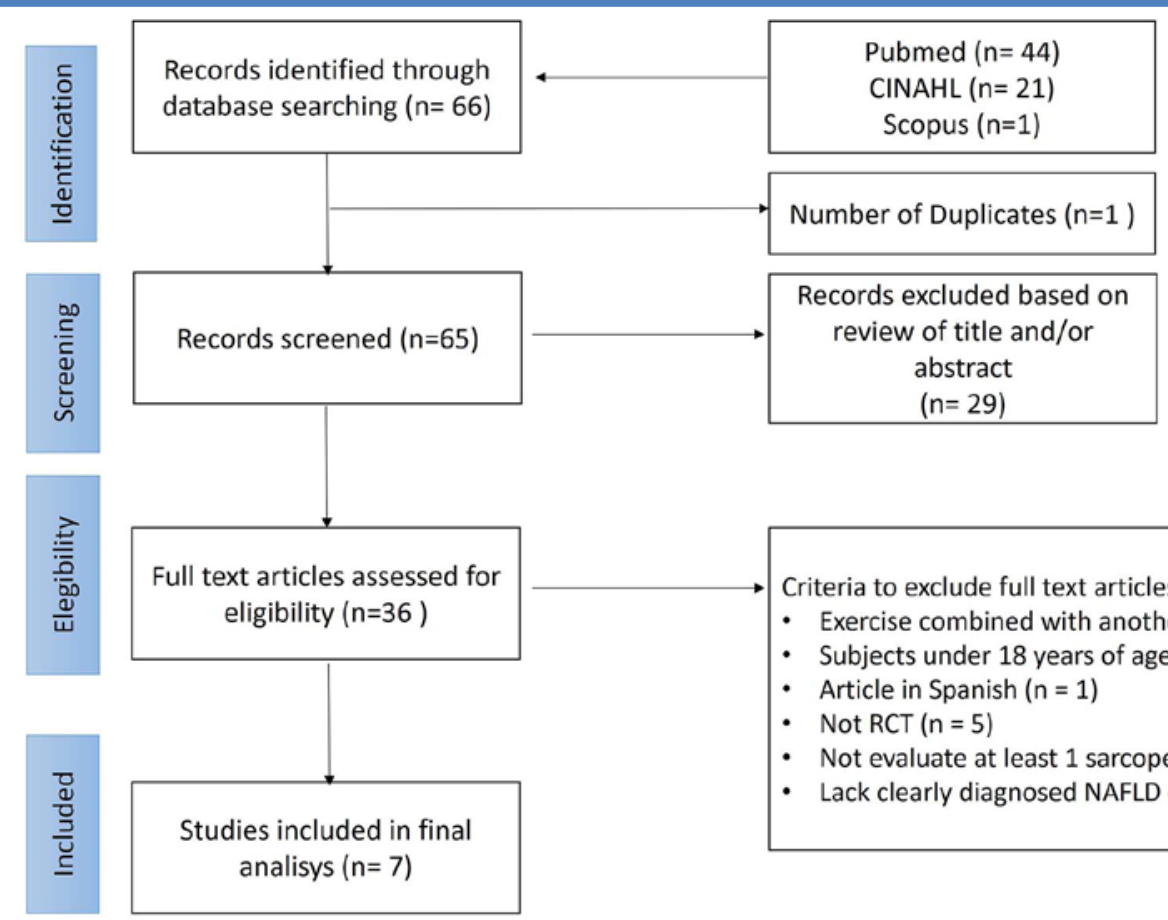

Fig 1. Flow chart to the PRISMA statement. Flow chart of search results and study selection according to the PRISMA statement. 
Exercise training in non-alcoholic fatty liver disease

Eur J Transl Myol 31 (1): 9630, 2021 doi: 10.4081/ejtm.2021.9630

\begin{tabular}{|c|c|c|c|c|c|c|c|c|c|}
\hline \multirow{2}{*}{$\begin{array}{ll}\text { Study } & \text { or } \\
\text { subgroup } & \\
\end{array}$} & \multicolumn{3}{|c|}{ Exercise } & \multicolumn{3}{|c|}{ Control } & \multicolumn{3}{|c|}{ Mean Difference } \\
\hline & Mean & SD & Total & Mean & SD & Total & Weight & IV, Random, 95\% Cl & Year \\
\hline Sullivan $2012^{21}$ & 24.8 & 5.2 & 12 & 19.9 & $\overline{6.1}$ & 6 & $27.4 \%$ & $4.90(-0.80,10.60)$ & 2012 \\
\hline Pugh $2013^{22}$ & 36.5 & 15.2 & 6 & 22.1 & 4.6 & 5 & $5.4 \%$ & $14.40(1.59,27.21)$ & 2013 \\
\hline Pugh $2014^{23}$ & 33.4 & 12.2 & 13 & 24.8 & 11.5 & 8 & $8.3 \%$ & $8.60(-1.77,18.97)$ & 2014 \\
\hline $\begin{array}{l}\text { Shojaee- } \\
\text { Moradie } 2016^{24}\end{array}$ & 33 & 5.8 & 15 & 23.8 & 4.5 & 12 & $58.9 \%$ & $9.20(5.31,13.09$ & 2016 \\
\hline Total (95\% CI) & & & 46 & & & 31 & $100.0 \%$ & $8.25(5.27,11.24)$ & \\
\hline
\end{tabular}

\section{Mean Difference}

IV, Random, $95 \% \mathrm{CI}$

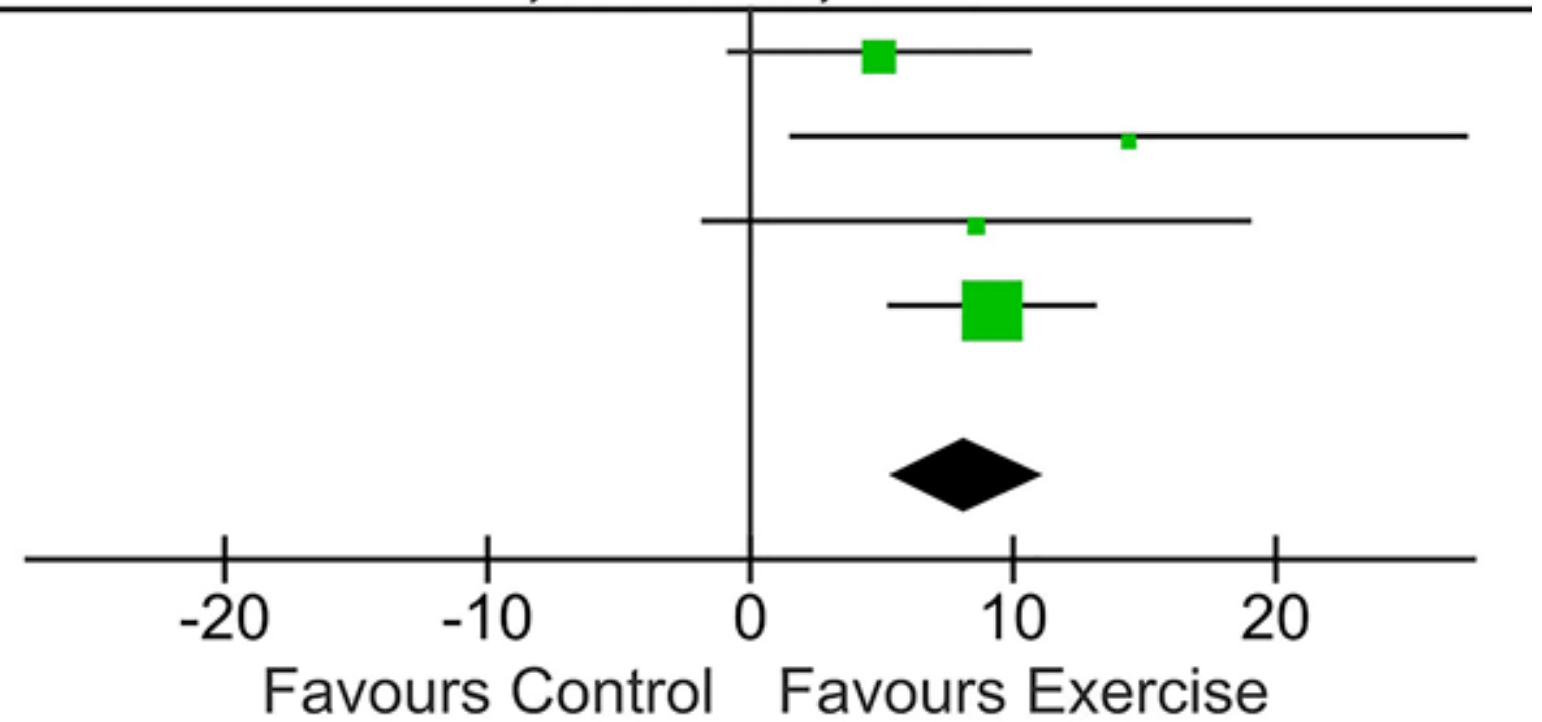

Fig 2. Forest Plot for physical performance. A meta-analysis of pooled effect size and confidence intervals (CIs) (95\%) of the interventions with exercise versus control group on physical performance evaluated by the cardiopulmonary exercise test (CPET) ( $\mathrm{mL} / \mathrm{Kg} * \mathrm{~min})$.

moderate, and 0.8 or higher as large effect size. ${ }^{32}$ Positive values indicated that it was favorable to the exercise intervention and vice versa. Zero value suggested that there was no effect on the analyzed variable.

\section{Heterogeneity}

We quantified heterogeneity using the $\chi^{2}$ test, where a significant $p$-value was indicative of more considerable heterogeneity. We also applied a complementary inconsistency test $\mathrm{I}^{2}$ and presented this with its corresponding 95\% CI to assess the degree of heterogeneity. Higher $\mathrm{I}^{2}$ values indicated more significant heterogeneity. ${ }^{33}$

\section{Risk of Bias}

We assessed all the included RCTs using the Cochrane collaboration risk of bias tool to search for elements that could over- or under-estimate the intervention's effect. We evaluated the following for each study: selection bias (random sequence and generations, allocation concealment), performance bias (blinding of participants and research staff), detection bias (blinding of outcome evaluation), attrition bias (incomplete outcome data), reporting bias (selective reporting), other sources of bias. 30 Two independent reviewers (AG and OA) performed 
the assessments; they discussed discrepancies until reaching a consensus.

\section{Results}

\section{Review studies}

We initially identified 66 articles in PubMed, CINAHL, and Scopus. Of these, we excluded one by duplication and 29 after analyzing the title and abstract. Among the remaining 36 articles, we excluded 29 due to the combination of exercise with another intervention $(\mathrm{n}=$ 15), participants under 18 years $(n=2)$, articles written in Spanish $(\mathrm{n}=1)$, reports not RCTs $(\mathrm{n}=5)$, no determination or evaluation of sarcopenia criteria $(n=2)$, and patients were not diagnosed with NAFLD or had comorbidities $(n=4)$. S4 contains the excluded studies list with the causes for the exclusion. ${ }^{34-61}$ We included seven articles in the final analysis (Figure 1). ${ }^{21-27}$

\section{Description of included studies}

A total of 182 participants were included in the analysis. Among them, 98 persons participated in exercise interventions and 84 in control groups (see Table 2). Five studies used a moderate-intensity protocol of endurance training. ${ }^{21-24,27}$ Three studies used a combined exercise protocol (endurance and resistance) ${ }^{24-26}$, and no study applied resistance training alone; in all seven studies, the exercise interventions were supervised. All the studies had a control group composed of patients with NAFLD following standard or conventional care, which did not include exercise intervention or any other component that could have influenced interest outcomes. ${ }^{21-27}$ Duration of exercise intervention ranged from 12-16 weeks, with training frequency of 2-5 times per week lasting 20-60 min per session. Endurance training intensity varied from $45-75 \%$ of oxygen consumption peak ( $\left.\mathrm{VO}_{2 \text { peak }}\right), 30-60 \%$ of heart rate reserve (HRR), or 16-18/20 (Borg Scale) rating of perceived exertion (RPE). Endurance training varied among cycle ergometer, treadmill, Nordic brisk walking, walking, and self-selected gymnasium exercise routines.

Two articles described high-intensity interval training (HIIT) as a form of endurance training. One of these articles used five intervals of $2 \mathrm{~min}$, adding $10 \mathrm{~s}$ to each range per week with 3 min of recovery and an RPE (Borg Scale) intensity of 16-17 (very hard). ${ }^{25}$ The other article used cycling intervals with an RPE (Borg scale) intensity of $16-18{ }^{26}$ In the remaining five studies patients performed continuous training. ${ }^{21-24,27}$

Among the three articles that carried out combined training, one performed a moderate-intensity endurance protocol (40\%-60\% HRR) combined with resistance training. However, the latter training details were not described. ${ }^{24}$ Another study used a combined training protocol by performing endurance interval training in cycling with an intensity based on RPE of 16-18 (very hard) and resistance training with an RPE intensity of 1416 (hard). The resistance training includes hip and knee extensions, horizontal rows, chest presses, and vertical rows. ${ }^{26}$ One article required participants to perform an interval on a cycle ergometer, followed by a light-bandresisted upper body exercise (60 s) in the following order: face-pull, horizontal push, horizontal pull, $30^{\circ}$ push. However, it was unclear whether this protocol was a combined workout. ${ }^{25}$

\section{Quality assessment analysis}

The TESTEX scale analysis yielded a median score of 11 out of 15 possible points for the studies, ${ }^{10}$ with values closer to 15 representing a higher quality than values closer to 1 . We evaluated assessment quality by organizing the studies as low-quality if their score was less than the median and high-quality if the score was greater than or equal to the median. ${ }^{10}$ Accordingly, six studies were of high quality, and one article was lowquality (Table 3). The main weaknesses TESTEX revealed were the supervision of physical activity in the control groups ( 0 of 7 articles), intention-to-treat analysis (1 of 7 studies), and blinding of the assessor for at least one key outcome (1 of 7 articles).

\section{Risk of bias assessment}

The risk of bias was low in the RCTs included in this systematic review and meta-analyses for every outcome (S5 and S6). However, we had some concerns about their analysis of physical performance regarding blinding the assessors. Only one of the studies performed this key methodological feature, indicating a potential risk of detection bias for articles that used a cardiopulmonary exercise test (CPET) to assess physical performance, as assessors might influence patients' performance in this type of evaluation. The details about the risk of bias assessment can be found in S5 and S6.

\section{Change in muscle strength}

The muscle strength criterion for sarcopenia was excluded because none of the selected studies evaluated it.

\section{Change in physical performance}

We performed a meta-analysis with the results obtained post-exercise by comparing the control group vs. the exercise group for the physical performance criterion. Data on physical performance were present in four studies, ${ }^{21-24}$ which determined the direct maximum oxygen consumption $\left(\mathrm{VO}_{2 \max }\right)$ or oxygen consumption peak $\left(\mathrm{VO}_{2 \text { peak }}\right)$ based on CPET and expressed in $\mathrm{mL} / \mathrm{Kg}^{*} \mathrm{~min}$. In this regard, we excluded one article because it performed the $2 \mathrm{Km}$ walking test, which does not directly evaluate physical performance. ${ }^{27}$ Three studies showed significant increases in $\mathrm{VO}_{2 \max }$ or $\mathrm{VO}_{\text {2peak. }}{ }^{22-24}$ One study showed no change; here, the authors recognized that a type II statistical error could explain the results because of the small number of participants. ${ }^{21}$ The pooled analysis of the studies indicated a change in physical performance in favour of exercise (MD $8.26 \mathrm{~mL} / \mathrm{Kg}^{*} \min$ [95\% CI 5.27-11.24 
Exercise training in non-alcoholic fatty liver disease

Eur J Transl Myol 31 (1): 9630, 2021 doi: 10.4081/ejtm.2021.9630

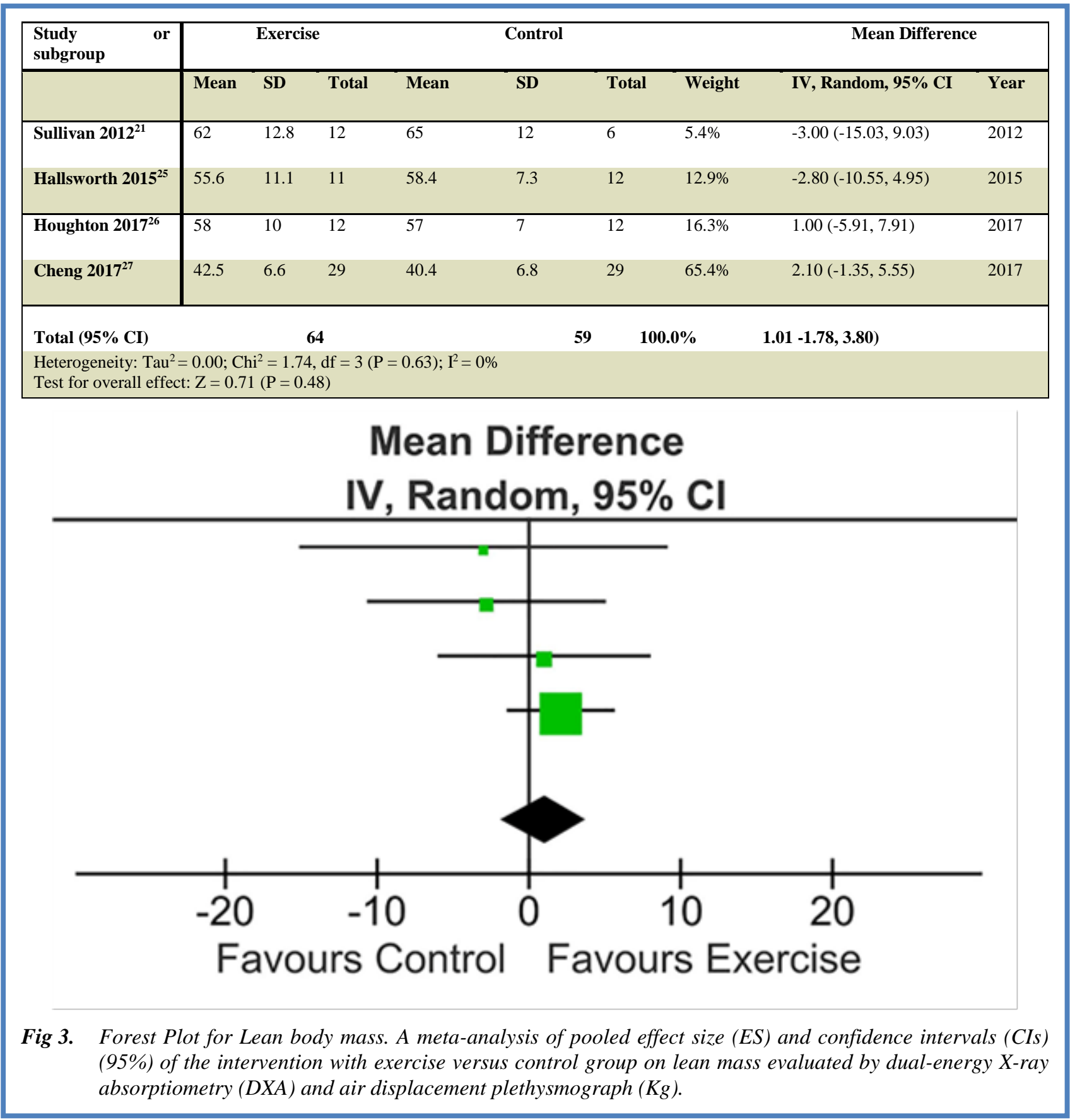

$\left.\mathrm{mL} / \mathrm{Kg}^{*} \mathrm{~min}\right], \mathrm{p}<0.0001$, Figure 2) and a large effect size (SMD 1.10 [0.60-1.60], $\mathrm{p}<0.0001, \mathrm{I}^{2}=0 \%$ ). Studies that analysed physical performance had low heterogeneity $\left(\mathrm{Chi}^{2} 2.43, \mathrm{p}=0.49 ; \mathrm{I}^{2} 0 \%\right.$; $\left.\mathrm{Tau}^{2}=0.00\right)$.

Change in muscle mass

Four studies determined muscle mass as lean body mass (LBM). ${ }^{21,25-27}$ They evaluated LBM by different methods, including dual-energy X-ray absorptiometry (DXA) and air displacement plethysmography. Despite this, we could compare the values they reported because they expressed the results in kilograms $(\mathrm{Kg})$. None of these studies reported changes in LBM. The studies that we used to analyse this outcome had low heterogeneity $\left(\mathrm{Chi}^{2}\right.$ 1.74, $\mathrm{p}=0.63$; $\mathrm{I}^{2} 0 \%$; $\mathrm{Tau}^{2}=0.00$ ); our meta-analysis found no evidence of a difference in the effect between exercise and control groups (MD 1.01 Kg [95\% CI -1.78 to $3.80 \mathrm{Kg}], \mathrm{p}=0.48$, Figure 3 ). There was a small effect size (SMD 0.09 [-0.27 to 0.44], $\mathrm{p}=0.64, \mathrm{I}^{2}=0 \%$ ).

\section{Discussion}

Following our results, we established the effect of exercise training, specifically endurance training and combined training in two of the three criteria for sarcopenia in NAFLD patients. According to our results, endurance and combined training positively impact 
physical performance and no impact on the LBM of NAFLD patients. It was impossible to determine the effect of exercise on NAFLD patients' muscle strength because no study determined it.

\section{Effect of exercise on muscle strength}

Some antecedents show the relationship between NAFLD status and muscle strength. ${ }^{62}$ A recent study suggests that a higher hepatic steatosis index (HIS), a clinical feature of NAFLD patients, is associated with lower muscle strength in both sexes. ${ }^{62}$ This antecedent suggests the relevance of muscle strength on NAFLD. Therefore, it is crucial to establish and analyze the influence of factors that could improve muscle strength in patients with NAFLD. There is consistent evidence that resistance training increases muscle strength. ${ }^{63-65}$ Despite clear antecedents that link increased muscle strength with resistance exercise, none of the RCTs included here featured resistance training as a sole intervention. Three studies used a combined exercise protocol (endurance and resistance). ${ }^{24-26}$ Despite the combined training, we expected them to evaluate physical qualities such as aerobic capacity and muscular strength; however, all the articles only assessed aerobic capacity. None of them evaluated muscle strength.

For this reason, we could not analyze muscle strength as a criterion of sarcopenia. Besides the conceptual importance of measuring muscle strength in studies that include resistance training, there are also methodological reasons. In general, muscle strength assessments are more straightforward and require less equipment than direct $\mathrm{VO}_{2 \max }$ or $\mathrm{VO}_{2 \text { peak }}$ determination. Concerning the methodology to measure muscle strength, the handgrip strength (HGS) test is one of the most used evidencebased methods for evaluating muscle strength. ${ }^{1} \mathrm{HGS}$ is a better predictor of adverse clinical outcomes than muscle mass. ${ }^{66}$ If HGS cannot be used, several alternative methodologies are available: knee flexion/extension, dynamometer, one maximum repetition (1RM), ten maximum repetitions (10RM), Isokinetic evaluation, and peak expiratory flow (specific to respiration). ${ }^{1}$ One recent study evaluated the relationship between NAFLD status and HGS using a cohort declared representative of the general Korean population. ${ }^{62}$ The results indicate that a higher HIS is associated with lower HGS in both sexes. ${ }^{62}$ Therefore, HGS, an assessment of overall strength in sarcopenia and NAFLD, is quick and easy to perform and should be used as a base procedure for evaluating muscle strength in patients with liver pathologies.,62 Future research should include muscle strength assessments to investigate the effects of exercise, especially resistance training, in NAFLD patients' sarcopenia.

\section{Effect of exercise on physical performance}

Physical performance, one of the criteria for a sarcopenia diagnosis, is widely evaluated using the CPET, which provides a global assessment of integrative physiological responses. ${ }^{67,68}$ Our study's meta-analysis indicates that most of the articles showed increased physical performance after the endurance and combined training protocol. Only one study found no changes in $\mathrm{VO}_{2 \text { peak }}$ after exercise training, which may be explained by the small sample size. ${ }^{21}$ The overall analysis revealed low heterogeneity and improved physical performance under exercise regardless of its features (type, intensity, duration). Three studies performed endurance training without another intervention, ${ }^{21-23}$ while one article performed combined resistance and endurance training. ${ }^{24}$ The endurance training parameters applied in these studies were consistent with the clinical practice guidelines for managing NAFLD from European associations to study the liver, diabetes, and obesity (EASL, EASD, EASO); they describe a comprehensive lifestyle approach for treating these patients. ${ }^{69}$ All the studies performed CPET and reported the $\mathrm{VO}_{2 \max }$ or $\mathrm{VO}_{\text {2peak }}$ as maximal aerobic capacity indicators, reflecting the respiratory and circulatory systems' ability to supply oxygen to skeletal muscles during exercise. ${ }^{70}$ They predicted an increase in oxygen consumption after endurance training, which induces adaptations in the cardiovascular system and increases mitochondrial biogenesis and capillary density in the skeletal muscles, improving the transport and oxygen use to generate energy. ${ }^{63,71}$ Zenith et al. in 2014 observed increases in $\mathrm{VO}_{2 \text { peak }}$ in cirrhotic patients after eight weeks of endurance training. ${ }^{60}$ This antecedent is consistent because the primary adaptation to endurance training is cardiorespiratory fitness improvement. ${ }^{72}$ Therefore, our meta-analysis showed that planned and supervised endurance and combined training improved physical performance in patients with sarcopenia associated with NAFLD. It is essential to mention that these patients should perform regular exercise to preserve its beneficial effects. This recommendation is based on the substantial benefits exercise training has on hepatic metabolism and the fat loss induced by endurance training. ${ }^{73-75}$ Thus, training is a therapeutic strategy for improving cardiorespiratory fitness in fatty liver disease. ${ }^{76}$ Furthermore, before liver transplantation, regular physical activity is essential to combatting patients' immediate stress post-transplant; it is also a critical determinant in long-term health after hepatic transplant. ${ }^{77}$ CPET is the gold standard for assessing cardiorespiratory fitness and functional capacity. Unlike tests that estimate oxygen consumption, CPET measures respiratory, cardiovascular, and neuromuscular system function. ${ }^{67,68}$ We excluded one study incorporated in our meta-analysis (in the muscle mass outcome) from the physical performance results, as oxygen consumption was determined from a $2 \mathrm{Km}$ walking test. ${ }^{27}$ In addition to the CPET assessment, the studies on patients with sarcopenia associated with NAFLD could include other validated muscle function tests for primary sarcopenia. For example, the short physical performance battery test (SPPB) evaluates gait, strength, and balance through a performance scoring system - it is an easy and quick test 
to implement. ${ }^{1,78}$ SPPB can assess sarcopenia's severity and predict mortality on the liver transplant waitlist. ${ }^{79,80}$ Future studies should use the SPPB to gain additional information on muscle function in NAFLD patients, as the European Association for the Study of the Liver (EASL) suggests. ${ }^{81}$

\section{Effect of exercise on muscle mass}

As shown in Figure 3, our results showed that endurance and combined training does not affect NAFLD patients' LBM - a conclusion based on our analysis of four studies. ${ }^{21,25-27}$ These studies determined LBM using plethysmography and DXA. Both methods are widely used to assess body composition in research. The studies showed considerable variability, but the variability across the studies was very consistent. The lack of significance in the overall effect may be because DXA determinations have low reproducibility, dependent upon the equipment used. The gold standard methods for measuring body composition, especially for muscular mass, are CT and magnetic resonance imaging (MRI). ${ }^{4}$ Considering that all the studies in the meta-analysis mainly comprised endurance training protocols as the central exercise intervention, it is possible that endurance training does not affect NAFLD patients' LBM. Our results are consistent with a systematic review of cirrhotic patients trained with endurance protocols, which reported no LBM changes. ${ }^{9,82}$ Contrary to these results, a study in cirrhotic patients featuring resistance training showed an increased muscle size. ${ }^{83}$ This observation suggests that the type of exercise training determines the effects on muscle mass and that resistance training could positively impact muscle mass in NAFLD patients.

\section{Exercise conditions to regulate sarcopenia}

Therapies to revert muscular mass loss in NAFLD patients include pharmacological and nutritional approaches. However, exercise-based treatments should not be excluded because they can improve the patients' generalized physical condition and life quality. ${ }^{8}$ It is widely established that resistance training is the most promising method to increase muscle strength and mass as well as balance; ${ }^{84}$ further, it can induce muscular hypertrophy, translating to increased muscle mass. ${ }^{84}$ Based on these antecedents, resistance training should be indicated as a therapy, alone or in combination, for sarcopenia in NAFLD patients. It is necessary to consider the conditions of resistance training to use in NAFLD patients. The standard conditions suggest that a high load induces a higher hypertrophic response in skeletal muscle; 85 however, loads below $30 \%$ of $1 \mathrm{RM}$ seem sufficient to trigger a hypertrophic response. The current recommendation for hypertrophic training is an intensity of $40-80 \%$ of the individual $1 \mathrm{RM}$, with loads $>60 \%$ to increase maximal force and muscular mass. ${ }^{86}$ Thus, the best conditions for resistance training in NAFLD patients require further study.

\section{Limitations}

As mentioned, the RCTs' main limitations included here were difficulty in blinding participants, therapists, and assessors and participants' non-adherence to the assigned intervention regimes. Blinding participants and researchers are a significant challenge in exercise RCTs, as lifestyle interventions require patients and therapists to be fully aware of the type of intervention to be delivered. Nonetheless, reducing the risk of bias is crucial to blind the outcome assessors, which must be clearly stated in the RCT report. As for non-adherence, researchers should include an intention to treat analyses in a prespecified fashion, considering that attrition is a common feature in exercise RCTs. Another limitation was the lack of supervision for not performing the physical activity in the control group. This monitoring is essential to ensuring a low level of physical activity that does not influence the results. If this variable is not controlled, then the sedentary controls could belong to a group that performs an unsupervised and undeclared exercise. These limitations should be considered in future RCTs. In our meta-analysis, the RCTs have a minimal sample size, making it necessary to interpret the results with very caution. In future RCTs, it would be essential to increase the sample size. The exercise training programs were significantly different among the studies regarding exercise intensity, total duration, session frequency, and modality (endurance or combined training). Among these, training modalities had special consideration since resistance training is one of the most potent interventions for increasing muscle size and quality in healthy and ill subjects. ${ }^{87}$ This issue is caused by increased synthesis of myofibrillar and mitochondrial proteins in untrained individuals and increased strength, muscle mass, and effort tolerance. ${ }^{63-65,72,88}$ Nevertheless, none of the studies used resistance training to treat NAFLD patients. Therefore, we strongly recommend including resistance training as the main component of exercise protocols in future research on sarcopenia in NAFLD patients. This high variability in physical training characteristics forces us to interpret the results of this research with caution. The lack of categorization of NAFLD severity in the RCT participants is another limitation of the studies. This categorization is fundamental to determine if the effect of exercise training on sarcopenia depends on the stage of the disease. Future RCTs should include this classification when planning and executing exercise protocols. Finally, this research limitation is the low amount of RCTs found for the meta-analysis, which hinders this analysis's conclusions.

\section{Conclusions}

Exercise training is a beneficial strategy to treat sarcopenia in NAFLD patients. Endurance and combined training increase physical function criteria but do not improve muscle mass criteria on sarcopenia in NAFLD patients. Nevertheless, these results might have been influenced by several independent factors, which were 
raised after analyzing the data for this review. Among these factors are the small number of patients included in the analyzed RCTs, the heterogeneity of the ET used in every study, the non-use of resistance training as part of the intervention, which is known to prevent sarcopenia and, the absence of muscle strength assessments in the RCTs included.

Therefore, we recommend that future research should consider resistance training and muscle strength evaluations to estimate its effects in this condition. The exercise training is beneficial for sarcopenia in NAFLD, but it is necessary more evidence to determine the best type of training that positively affects all the sarcopenia components.

\section{List of acronyms}

ADP - Air-displacement plethysmography

AST - aspartate transaminase

ALT - alanine transaminase

CG - control group

CINAHL - Cumulative Index of Nursing and Allied Health Literature

CIs - confidence intervals

CLD - chronic liver disease

CPET - cardiopulmonary exercise test

CT - computed tomography

DXA - dual-energy X-ray absorptiometry

ET- exercise training

EWGSOP - European Working Group on Sarcopenia in Older People

EX - exercise group

GGT - gamma-glutamyl transpeptidase

HGS - handgrip strength

HIIT - high-intensity interval training

HRR - heart rate reserve

ITT - intention-to-treat

LBM - lean body mass

MD - mean differences

$\mathrm{MM}$ - muscle mass

MRS - nuclear magnetic resonance spectroscopy

NA - not applicable

NAFLD - Non-alcoholic fatty liver disease

NASH - non-alcoholic steatohepatitis

NR - not reported

PICO - population, intervention, comparison question (control), and outcomes

PP - Physical performance

PRISMA - Preferred Reporting Items for Systematic Reviews and Meta-Analysis

PROSPERO - Prospective Register of Systematic Reviews

PubMed - Public MEDLINE

RCTs - randomized controlled trials

RPE - rating of perceived exertion

SMD - standardized mean differences

TESTEX - Tool for the assEssment of Study qualiTy and reporting in EXercise

$\mathrm{VO}_{2 \max }$ - maximum oxygen consumption
$\mathrm{VO}_{2 \text { peak }}$ - oxygen consumption peak

1RM - one maximum repetition

10RM - ten maximum repetitions

2-Km WT - 2 km walking test

$\mathrm{x} / \mathrm{wk}$ - times per week

wk - week

\section{Authors contributions}

AG, CC-V, FS, and OA had full access to all of the data in the study and takes responsibility for the integrity of the data and the accuracy of the data analysis; OA contributed to the study design, statistical analysis, and interpretation of the results, and CH-S, FS, and M.V-B contributed to the study design and writing of the manuscript.

All named authors meet the International Committee of Medical Journal Editors (ICMJE) criteria for authorship for this article, take responsibility for the work's integrity as a whole, and have given their approval for this version to be published.

\section{Acknowledgments}

We acknowledge Orlando Flores Guerrero PhD., Faculty of Health and Behavioural Sciences, The University of Queensland, for his input while drafting the manuscript.

\section{Funding}

The manuscript was supported by research grants from the National Fund for Science and Technological Development (FONDECYT 1200944 [CC-V], 1201039 [FS]), the Millennium Institute on Immunology and Immunotherapy (P09-016-F [CC-V, FS]) and BASAL Grant - CEDENNA from the National Research and Development Agency (ANID), Government of Chile (AFB180001 [CC-V]). The Millennium Nucleus of Ion Channel-Associated Diseases (MiNICAD) is supported by the Iniciativa Científica Milenio (ANID, Chile).

\section{Conflict of Interest}

The author declares no competing interests.

\section{Ethical Publication Statement}

I confirm that I have read the Journal's position on ethical publication issues and affirms that this report is consistent with those guidelines.

\section{Corresponding Author}

Claudio Cabello-Verrugio. Laboratory of Muscle Pathology, Fragility, and Aging. Department of Biological Sciences. Faculty of Life Sciences. Universidad Andres Bello, Postal code: 8370146. Email: claudio.cabello@unab.cl

\section{E-mails and ORCID iD of CoAuthors}

Andrea Gonzalez: a.gonzalezrojas@uandresbello.edu ORCIDiD: 0000-0001-5003-7109

Mayalen Valero-Breton: m.valerobreton@uandresbello.edu ORCI iD: 0000-0001-6552-2262 
Camila Huerta-Salgado:

ORCID iD: 0000-0002-4166-2217

c.huertasalgado@uandresbello.edu

Oscar Achiardi: oscar.achiardi@pucv.cl

ORCID iD: 0000-0003-3623-0994

Felipe Simon: fsimon@unab.cl

ORCID iD: 0000-0002-2653-9798

\section{References}

1. El Sherif O, Dhaliwal A, Newsome PN,Armstrong MJ. Sarcopenia in nonalcoholic fatty liver disease: new challenges for clinical practice. Expert Rev Gastroenterol Hepatol 2020; 14: 197-205. doi:10.1080/17474124.2020.1731303.

2 Chalasani N, Younossi Z, Lavine JE, Diehl AM, Brunt EM, Cusi K, Charlton M,Sanyal AJ. The diagnosis and management of non-alcoholic fatty liver disease: practice Guideline by the American Association for the Study of Liver Diseases, American College of Gastroenterology, and the American Gastroenterological Association. Hepatology 2012; 55: 2005-23. doi:10.1002/hep. 25762.

3 Yu R, Shi Q, Liu L,Chen L. Relationship of sarcopenia with steatohepatitis and advanced liver fibrosis in non-alcoholic fatty liver disease: a metaanalysis. BMC Gastroenterol 2018; 18: 51. doi:10.1186/s12876-018-0776-0.

4 Cruz-Jentoft AJ, Bahat G, Bauer J, Boirie Y, Bruyere O, Cederholm T, Cooper C, Landi F, Rolland Y, Sayer AA, Schneider SM, Sieber CC, Topinkova E, Vandewoude M, Visser M, Zamboni M, Writing Group for the European Working Group on Sarcopenia in Older P,the Extended Group for E. Sarcopenia: revised European consensus on definition and diagnosis. Age Ageing 2019; 48: 601. doi:10.1093/ageing/afz046.

5 Lee YH, Jung KS, Kim SU, Yoon HJ, Yun YJ, Lee BW, Kang ES, Han KH, Lee HC,Cha BS. Sarcopaenia is associated with NAFLD independently of obesity and insulin resistance: Nationwide surveys (KNHANES 2008-2011). J Hepatol 2015; 63: 486-93. doi:10.1016/j.jhep.2015. 02.051.

6 Dasarathy S. Treatment to improve nutrition and functional capacity evaluation in liver transplant candidates. Curr Treat Options Gastroenterol 2014; 12: 242-55. doi:10.1007/s11938-014-0016-9.

7 Meeks AC,Madill J. Sarcopenia in liver transplantation: A review. Clin Nutr ESPEN 2017; 22: 76-80. doi:10.1016/j.clnesp.2017.08.005.

8 Tandon P, Dunn MA,Duarte-Rojo A. Resistance Training Reduces Risk of Sarcopenia in Patients With Cirrhosis. Clin Gastroenterol Hepatol 2020; 18: 1036-9. doi:10.1016/j.cgh.2019.09.030

9 Aamann L, Dam G, Rinnov AR, Vilstrup H,Gluud LL. Physical exercise for people with cirrhosis.
Cochrane Database Syst Rev 2018; 12: CD012678. doi:10.1002/14651858.CD012678.pub2

10 Smart NA, King N, McFarlane JR, Graham PL,Dieberg G. Effect of exercise training on liver function in adults who are overweight or exhibit fatty liver disease: a systematic review and metaanalysis. Br J Sports Med 2018; 52: 834-43. doi:10.1136/bjsports-2016-096197.

11 Medrano M, Cadenas-Sanchez C, Álvarez-Bueno C, Cavero-Redondo I, Ruiz JR, Ortega FB,Labayen I. Evidence-Based Exercise Recommendations to Reduce Hepatic Fat Content in Youth- a Systematic Review and Meta-Analysis. Prog Cardiovasc Dis 2018; 61: 222-31. doi:10.1016/j.pcad.2018.01.013.

12 Guyatt GH, Oxman AD, Kunz R, Atkins D, Brozek J, Vist G, Alderson P, Glasziou P, Falck-Ytter Y,Schunemann HJ. GRADE guidelines: 2. Framing the question and deciding on important outcomes. $\mathrm{J}$ Clin Epidemiol 2011; 64: 395-400. doi:10.1016/ j.jclinepi.2010.09.012.

13 Younossi ZM. Nonalcoholic fatty liver disease and nonalcoholic steatohepatitis: Implications for liver transplantation. Liver Transpl 2018; 24: 166-70. doi:10.1002/lt.25003.

14 Perumpail BJ, Khan MA, Yoo ER, Cholankeril G, Kim D,Ahmed A. Clinical epidemiology and disease burden of nonalcoholic fatty liver disease. World J Gastroenterol 2017; 23: 8263-76. doi:10.3748/wjg.v23.i47.8263.

15 van Deursen VM, Damman K, Hillege HL, van Beek AP, van Veldhuisen DJ,Voors AA. Abnormal liver function in relation to hemodynamic profile in heart failure patients. J. Card. Fail. 2010; 16: 84-90. doi:10.1016/j.cardfail.2009.08.002.

16 Kong LZ, Chandimali N, Han YH, Lee DH, Kim JS, Kim SU, Kim TD, Jeong DK, Sun HN, Lee DS,Kwon T. Pathogenesis, Early Diagnosis, and Therapeutic Management of Alcoholic Liver Disease. Int J Mol Sci 2019; 20: 2712. doi:10.3390 /ijms20112712.

17 Engelking LR, Dasher CA,Hirschowitz BI. Withinday fluctuations in serum bile-acid concentrations among normal control subjects and patients with hepatic disease. Am J Clin Pathol 1980; 73: 196201. doi:10.1093/ajcp/73.2.196.

18 Suchomel TJ, Nimphius S,Stone MH. The Importance of Muscular Strength in Athletic Performance. Sports Med 2016; 46: 1419-49. doi:10.1007/s40279-016-0486-0.

19 Heymsfield SB, McManus C, Smith J, Stevens V,Nixon DW. Anthropometric measurement of muscle mass: revised equations for calculating bone-free arm muscle area. Am J Clin Nutr 1982; 36: 680-90. doi:10.1093/ajcn/36.4.680.

20 Beaudart C, Rolland Y, Cruz-Jentoft AJ, Bauer JM, Sieber C, Cooper C, Al-Daghri N, Araujo de Carvalho I, Bautmans I, Bernabei R, Bruyere O, Cesari M, Cherubini A, Dawson-Hughes B, Kanis 
JA, Kaufman JM, Landi F, Maggi S, McCloskey E, Petermans J, Rodriguez Manas L, Reginster JY, Roller-Wirnsberger R, Schaap LA, Uebelhart D, Rizzoli RFielding RA. Assessment of Muscle Function and Physical Performance in Daily Clinical Practice : A position paper endorsed by the European Society for Clinical and Economic Aspects of Osteoporosis, Osteoarthritis and Musculoskeletal Diseases (ESCEO). Calcif Tissue Int 2019; 105: 1-14. doi:10.1007/s00223-01900545-w.

21 Sullivan S, Kirk EP, Mittendorfer B, Patterson BW,Klein S. Randomized trial of exercise effect on intrahepatic triglyceride content and lipid kinetics in nonalcoholic fatty liver disease. Hepatology 2012; 55: 1738-45. doi:10.1002/hep.25548.

22 Pugh CJ, Cuthbertson DJ, Sprung VS, Kemp GJ, Richardson P, Umpleby AM, Green DJ, Cable NT,Jones H. Exercise training improves cutaneous microvascular function in nonalcoholic fatty liver disease. Am J Physiol Endocrinol Metab 2013; 305: E50-8. doi:10.1152/ajpendo.00055.2013.

23 Pugh CJ, Spring VS, Kemp GJ, Richardson P, Shojaee-Moradie F, Umpleby AM, Green DJ, Cable NT, Jones H,Cuthbertson DJ. Exercise training reverses endothelial dysfunction in nonalcoholic fatty liver disease. Am J Physiol Heart Circ Physiol 2014; 307: H1298-306. doi:10.1152/ajpheart.00306 2014 .

24 Shojaee-Moradie F, Cuthbertson DJ, Barrett M, Jackson NC, Herring R, Thomas EL, Bell J, Kemp GJ, Wright J,Umpleby AM. Exercise Training Reduces Liver Fat and Increases Rates of VLDL Clearance But Not VLDL Production in NAFLD. The Journal of Clinical Endocrinology \& Metabolism 2016; 101: 4219-28. doi:10.1210/jc. 2016-2353.

25 Hallsworth K, Thoma C, Hollingsworth KG, Cassidy S, Anstee QM, Day CP,Trenell MI. Modified high-intensity interval training reduces liver fat and improves cardiac function in nonalcoholic fatty liver disease: a randomized controlled trial. Clin Sci (Lond) 2015; 129: 1097 105. doi:10.1042/CS20150308.

26 Houghton D, Thoma C, Hallsworth K, Cassidy S, Hardy T, Burt AD, Tiniakos D, Hollingsworth KG, Taylor R, Day CP, McPherson S, Anstee QM,Trenell MI. Exercise Reduces Liver Lipids and Visceral Adiposity in Patients With Nonalcoholic Steatohepatitis in a Randomized Controlled Trial. Clin Gastroenterol Hepatol. 2017; 15: 96-102.e3. doi:10.1016/j.cgh.2016.07.031.

27 Cheng S, Ge J, Zhao C, Le S, Yang Y, Ke D, Wu N, Tan X, Zhang X, Du X, Sun J, Wang R, Shi Y, Borra RJH, Parkkola R, Wiklund P,Lu D. Effect of aerobic exercise and diet on liver fat in pre-diabetic patients with non-alcoholic-fatty-liver-disease: A randomized controlled trial. Sci Rep 2017; 7: 15952. doi:10.1038/s41598-017-16159-x.

28 Smart NA, Waldron M, Ismail H, Giallauria F, Vigorito C, Cornelissen V,Dieberg G. Validation of a new tool for the assessment of study quality and reporting in exercise training studies: TESTEX. Int J Evid Based Healthc 2015; 13: 9-18. doi:10.1097 /XEB.0000000000000020.

29 Oxfeldt M, Overgaard K, Hvid LG,Dalgas U. Effects of plyometric training on jumping, sprint performance, and lower body muscle strength in healthy adults: A systematic review and metaanalyses. Scand J Med Sci Sports 2019; 29: 145365. doi:10.1111/sms.13487.

30 Review Manager (RevMan) [Computer program] v. 5.4 (The Cochrane Collaboration, 2020).

31 Takeshima N, Sozu T, Tajika A, Ogawa Y, Hayasaka Y,Furukawa TA. Which is more generalizable, powerful and interpretable in metaanalyses, mean difference or standardized mean difference? BMC Med Res Methodol 2014; 14: 30. doi:10.1186/1471-2288-14-30.

32 Cohen J. Statistical Power Analysis for the Behavioral Sciences. (Routledge, 1988).

33 Higgins JP,Thompson SG. Quantifying heterogeneity in a meta-analysis. Stat Med 2002; 21: 1539-58. doi:10.1002/sim.1186. .

34 Franco I, Bianco A, Diaz MDP, Bonfiglio C, Chiloiro M, Pou SA, Becaria Coquet J, Mirizzi A, Nitti A, Campanella A, Leone CM, Caruso MG, Correale M,Osella AR. Effectiveness of two physical activity programs on non-alcoholic fatty liver disease. a randomized controlled clinical trial. Rev Fac Cien Med Univ Nac Cordoba 2019; 76: 2636. doi:10.31053/1853.0605.v76.n1.21638.

35 Katsagoni CN, Papatheodoridis GV, Ioannidou P, Deutsch M, Alexopoulou A, Papadopoulos N, Papageorgiou MV, Fragopoulou E,Kontogianni MD. Improvements in clinical characteristics of patients with non-alcoholic fatty liver disease, after an intervention based on the Mediterranean lifestyle: a randomised controlled clinical trial. $\mathrm{Br} \mathrm{J}$ Nutr 2018; 120: 164-75. doi:10.1017/S00071145 1800137X.

36 Axley P, Kodali S, Kuo YF, Ravi S, Seay T, Parikh NM,Singal AK. Text messaging approach improves weight loss in patients with nonalcoholic fatty liver disease: A randomized study. Liver Int 2018; 38: 924-31. doi:10.1111/liv.13622.

37 Draz RS, Serry ZMH, Rahmy AF, El Bardesi MS,Taha MM. Electroacupuncture Versus Aerobic Interval Training on Liver Functions in Patients with Nonalcoholic Fatty Liver. J Altern Complement Med 2020; 26: 51-7. doi:10.1089/acm.2019.0182.

38 Abd El-Kader SM, Al-Shreef FM,Al-Jiffri OH. Biochemical parameters response to weight loss in patients with non-alcoholic steatohepatitis. Afr 
Health Sci 2016; 16: 242-9. doi:10.4314/ahs.v16 i1.32.

39 Skrypnik D, Ratajczak M, Karolkiewicz J, Mądry E, Pupek-Musialik D, Hansdorfer-Korzon R, Walkowiak J, Jakubowski H,Bogdański P. Effects of endurance and endurance-strength exercise on biochemical parameters of liver function in women with abdominal obesity. Biomed Pharmacother 2016; 80: 1-7. doi:10.1016/j.biopha.2016.02.017

40 Yoshimura E, Kumahara H, Tobina T, Matsuda T, Ayabe M, Kiyonaga A, Anzai K, Higaki Y,Tanaka H. Lifestyle intervention involving calorie restriction with or without aerobic exercise training improves liver fat in adults with visceral adiposity. J Obes 2014; 2014: 197216. doi:10.1155/2014/ 197216.

41 Zelber-Sagi S, Buch A, Yeshua H, Vaisman N, Webb M, Harari G, Kis O, Fliss-Isakov N, Izkhakov E, Halpern Z, Santo E, Oren R,Shibolet O. Effect of resistance training on non-alcoholic fatty-liver disease a randomized-clinical trial. World J Gastroenterol 2014; 20: 4382-92. doi:10.3748/wjg. v20.i15.4382.

42 Straznicky NE, Lambert EA, Grima MT, Eikelis N, Nestel PJ, Dawood T, Schlaich MP, Masuo K, Chopra R, Sari CI, Dixon JB, Tilbrook AJ,Lambert GW. The effects of dietary weight loss with or without exercise training on liver enzymes in obese metabolic syndrome subjects. Diabetes Obes Metab 2012; 14: 139-48. doi:10.1111/j.1463-1326.2011. 01497.x.

43 St George A, Bauman A, Johnston A, Farrell G, Chey T,George J. Effect of a lifestyle intervention in patients with abnormal liver enzymes and metabolic risk factors. J Gastroenterol Hepatol 2009; 24: 399-407. doi:10.1111/j.1440-1746.2008. 05694.x.

44 Promrat K, Kleiner DE, Niemeier HM, Jackvony E, Kearns M, Wands JR, Fava JL,Wing RR. Randomized controlled trial testing the effects of weight loss on nonalcoholic steatohepatitis. Hepatology 2010; 51: 121-9. doi:10.1002/hep. 23276.

45 Winn NC, Liu Y, Rector RS, Parks EJ, Ibdah JA,Kanaley JA. Energy-matched moderate and high intensity exercise training improves nonalcoholic fatty liver disease risk independent of changes in body mass or abdominal adiposity - A randomized trial. Metabolism 2018; 78: 128-40. doi:10.1016/j. metabol.2017.08.012.

46 Garcia AMC, Veneroso CE, Soares DD, Lima AS,Correia MITD. Effect of a Physical Exercise Program on the Functional Capacity of Liver Transplant Patients. Transplantation Proceedings 2014; 46: 1807-8. doi:10.1016/j.transproceed.2014. 05.023.

47 Rachakonda V, Wills R, DeLany JP, Kershaw EE,Behari J. Differential Impact of Weight Loss on
Nonalcoholic Fatty Liver Resolution in a North American Cohort with Obesity. Obesity (Silver Spring) 2017; 25: 1360-8. doi:10.1002/oby.21890.

48 Galbreath M, Campbell, B., LaBounty, P., Bunn, J., Dove, J., Harvey, T., Hudson, G., Gutierrez, J., Levers, K., Galvan, E., Jagim, A., Greenwood, L., Cooke, M., Greenwood, M., Rasmussen, C., \& Kreider, R. Effects of Adherence to a Higher Protein Diet on Weight Loss, Markers of Health, and Functional Capacity in Older Women Participating in a Resistance-Based Exercise Program. Nutrients 2018; 10: 8. doi:10.3390/nu 10081070.

49 de Piano A, de Mello MT, Sanches Pde L, da Silva PL, Campos RM, Carnier J, Corgosinho F, Foschini D, Masquio DL, Tock L, Oyama LM, do Nascimento CM, Tufik S,Damaso AR. Long-term effects of aerobic plus resistance training on the adipokines and neuropeptides in nonalcoholic fatty liver disease obese adolescents. Eur J Gastroenterol Hepatol 2012; 24: 1313-24. doi:10.1097/MEG. 0b013e32835793ac.

50 Lee S, Bacha F, Hannon T, Kuk JL, Boesch C,Arslanian S. Effects of aerobic versus resistance exercise without caloric restriction on abdominal fat, intrahepatic lipid, and insulin sensitivity in obese adolescent boys: a randomized, controlled trial. Diabetes 2012; 61: 2787-95. doi:10.2337/ db12-0214.

51 Sanchez-Munoz V, Salas-Romero R, Del VillarMorales A, Martinez-Coria E, Pegueros-Perez A,Franco-Sanchez JG. [Decrease of liver fat content by aerobic exercise or metformin therapy in overweight or obese women]. Rev Invest Clin 2013; 65: 307-17

52 Brouwers B, Schrauwen-Hinderling VB, Jelenik T, Gemmink A, Sparks LM, Havekes B, Bruls Y, Dahlmans D, Roden M, Hesselink MKC,Schrauwen P. Exercise training reduces intrahepatic lipid content in people with and people without nonalcoholic fatty liver. Am J Physiol Endocrinol Metab 2018; 314: E165-E73. doi:10. 1152/ajpendo.00266.2017.

53 Pugh CJA, Sprung VS, Jones H, Richardson P, Shojaee-Moradie F, Umpleby AM, Green DJ, Cable NT, Trenell MI, Kemp GJ,Cuthbertson DJ. Exercise-induced improvements in liver fat and endothelial function are not sustained 12 months following cessation of exercise supervision in nonalcoholic fatty liver disease. International Journal of Obesity 2016; 40: 1927-30. doi:10.1038 /ijo.2016.123.

54 Debette-Gratien M, Tabouret T, Antonini MT, Dalmay F, Carrier P, Legros R, Jacques J, Vincent F, Sautereau D, Samuel D,Loustaud-Ratti V. Personalized adapted physical activity before liver transplantation: acceptability and results. 
Transplantation 2015; 99: 145-50. doi:10.1097/TP. 0000000000000245.

55 Devries MC, Samjoo IA, Hamadeh MJ, Tarnopolsky MA. Effect of endurance exercise on hepatic lipid content, enzymes, and adiposity in men and women. Obesity (Silver Spring) 2008; 16: 2281-8. doi:10.1038/oby.2008.358.

56 Yoo HJ, Hwang SY, Cho GJ, Hong HC, Choi HY, Hwang TG, Kim SM, Blüher M, Youn B-S, Baik SH,Choi KM. Association of Glypican-4 With Body Fat Distribution, Insulin Resistance, and Nonalcoholic Fatty Liver Disease. The Journal of Clinical Endocrinology \& Metabolism 2013; 98: 2897-901. doi:10.1210/jc.2012-4297.

57 Zhang HJ, Pan LL, Ma ZM, Chen Z, Huang ZF, Sun Q, Lu Y, Han CK, Lin MZ, Li XJ, Yang SY,Li XY. Long-term effect of exercise on improving fatty liver and cardiovascular risk factors in obese adults: A 1-year follow-up study. Diabetes Obes Metab 2017; 19: 284-9. doi:10.1111/dom.12809.

58 Abdelbasset WK, Tantawy SA, Kamel DM, Alqahtani BA, Elnegamy TE, Soliman GS,Ibrahim AA. Effects of high-intensity interval and moderate-intensity continuous aerobic exercise on diabetic obese patients with nonalcoholic fatty liver disease: A comparative randomized controlled trial. Medicine (Baltimore) 2020; 99: e19471. doi:10. 1097/MD.0000000000019471.

59 Kim H, Kim M, Kojima N, Fujino K, Hosoi E, Kobayashi H, Somekawa S, Niki Y, Yamashiro Y,Yoshida H. Exercise and Nutritional Supplementation on Community-Dwelling Elderly Japanese Women With Sarcopenic Obesity: A Randomized Controlled Trial. J Am Med Dir Assoc 2016; 17: 1011-9. doi:10.1016/j.jamda.2016. 06.016.

60 Zenith L, Meena N, Ramadi A, Yavari M, Harvey A, Carbonneau M, Ma M, Abraldes JG, Paterson I, Haykowsky MJ,Tandon P. Eight weeks of exercise training increases aerobic capacity and muscle mass and reduces fatigue in patients with cirrhosis. Clin Gastroenterol Hepatol 2014; 12: 1920-6 e2. doi:10. 1016/j.cgh.2014.04.016.

61 Johnson NA, Sachinwalla T, Walton DW, Smith K, Armstrong A, Thompson MW,George J. Aerobic exercise training reduces hepatic and visceral lipids in obese individuals without weight loss. Hepatology 2009; 50: 1105-12. doi:10.1002/hep. 23129.

62 Kim BJ, Ahn SH, Lee SH, Hong S, Hamrick MW, Isales CM,Koh JM. Lower hand grip strength in older adults with non-alcoholic fatty liver disease: a nationwide population-based study. Aging (Albany NY) 2019; 11: 4547-60. doi:10.18632/aging. 102068.

63 Hawley JA, Hargreaves M, Joyner MJ,Zierath JR. Integrative biology of exercise. Cell 2014; 159: 738-49. doi:10.1016/j.cell.2014.10.029.
64 Liu TC, Liu G, Hu SJ, Zhu L, Yang XB,Zhang QG. Quantitative Biology of Exercise-Induced Signal Transduction Pathways. Adv Exp Med Biol 2017; 977: 419-24. doi:10.1007/978-3-319-55231-6_54.

65 Francaux M,Deldicque L. Exercise and the control of muscle mass in human. Pflugers Arch 2019; 471: 397-411. doi:10.1007/s00424-018-2217-x.

66 Lauretani F, Russo CR, Bandinelli S, Bartali B, Cavazzini C, Di Iorio A, Corsi AM, Rantanen T, Guralnik JM,Ferrucci L. Age-associated changes in skeletal muscles and their effect on mobility: an operational diagnosis of sarcopenia. J Appl Physiol (1985) 2003; 95: 1851-60. doi:10.1152/jappl physiol.00246.2003.

67 Milani RV, Lavie CJ, Mehra MR,Ventura HO. Understanding the basics of cardiopulmonary exercise testing. Mayo Clin Proc 2006; 81: 160311. doi:10.4065/81.12.1603.

68 Weisman IM, Weisman IM, Marciniuk D, Martinez FJ, Sciurba F, Sue D,Sietsema K. ATS/ACCP Statement on Cardiopulmonary Exercise Testing. American Journal of Respiratory and Critical Care Medicine 2003; 167: 211-77. doi:10.1164/rccm. 167.2.211.

69 Marchesini G, Day CP, Dufour JF, Canbay A, Nobili V, Ratziu V,Mathus-Vliegen L. EASLEASD-EASO Clinical Practice Guidelines for the Management of Non-Alcoholic Fatty Liver Disease. Obesity Facts 2016; 9: 56-90. doi:10.1159/ 000443344.

70 Lee I, Kim J,Kang H. Estimated Cardiorespiratory Fitness Attenuates the Impacts of Sarcopenia and Obesity on Non-Alcoholic Fatty Liver in Korean Adults. Int J Environ Res Public Health 2020; 17: 3902. doi:10.3390/ijerph17113902.

71 Hughes DC, Ellefsen S,Baar K. Adaptations to Endurance and Strength Training. LID 10.1101/cshperspect.a029769 [doi] LID - a029769. Cold Spring Harb Perspect Med 2018; 8. doi:10.1101/cshperspect.a029769.

72 McGee SL,Hargreaves M. Exercise adaptations: molecular mechanisms and potential targets for therapeutic benefit. Nat Rev Endocrinol 2020; 16: 495-505. doi:10.1038/s41574-020-0377-1.

73 Lo MS, Lin LL, Yao WJ,Ma MC. Training and detraining effects of the resistance vs. endurance program on body composition, body size, and physical performance in young men. J Strength Cond Res 2011; 25: 2246-54. doi:10.1519/JSC. 0b013e3181e8a4be.

74 Nolan PB, Keeling SM, Robitaille CA, Buchanan CA,Dalleck LC. The Effect of Detraining after a Period of Training on Cardiometabolic Health in Previously Sedentary Individuals. Int J Environ Res Public Health 2018; 15: 2303. doi:10.3390/ijerph 15102303.

75 Brouwers B, Hesselink MK, Schrauwen $\mathrm{P}$,Schrauwen-Hinderling VB. Effects of exercise 


\section{Exercise training in non-alcoholic fatty liver disease}

Eur J Transl Myol 31 (1): 9630, 2021 doi: 10.4081/ejtm.2021.9630

training on intrahepatic lipid content in humans. Diabetologia 2016; 59: 2068-79. doi:10.1007/s00 125-016-4037-x. .

76 van der Windt DJ, Sud V, Zhang H, Tsung A,Huang $H$. The Effects of Physical Exercise on Fatty Liver Disease. Gene Expr 2018; 18: 89-101. doi:10.3727 /105221617X15124844266408.

77 Dunn MA, Rogal SS, Duarte-Rojo A,Lai JC. Physical Function, Physical Activity, and Quality of Life After Liver Transplantation. Liver Transpl 2020; 26: 702-8. doi:10.1002/lt.25742.

78 Phu S, Kirk B, Bani Hassan E, Vogrin S, Zanker J, Bernardo S,Duque G. The diagnostic value of the Short Physical Performance Battery for sarcopenia. BMC Geriatr 2020; 20: 242. doi:10.1186/s12877020-01642-4.

79 Lai JC, Feng S, Terrault NA, Lizaola B, Hayssen H,Covinsky K. Frailty predicts waitlist mortality in liver transplant candidates. American journal of transplantation : official journal of the American Society of Transplantation and the American Society of Transplant Surgeons 2014; 14: 1870-9. doi:10.1111/ajt.12762.

80 Wang CW, Feng S, Covinsky KE, Hayssen H, Zhou LQ, Yeh BM,Lai JC. A Comparison of Muscle Function, Mass, and Quality in Liver Transplant Candidates: Results From the Functional Assessment in Liver Transplantation Study. Transplantation 2016; 100: 1692-8. doi:10.1097/TP .0000000000001232 .

81 European Association for the Study of the Liver. Electronic address eee,European Association for the Study of the L. EASL Clinical Practice Guidelines on nutrition in chronic liver disease. J Hepatol 2019; 70: 172-93. doi:10.1016/j.jhep. 2018.06.024.

82 Naseer M, Turse EP, Syed A, Dailey FE, Zatreh M,Tahan V. Interventions to improve sarcopenia in cirrhosis: A systematic review. World J Clin Cases 2019; 7: 156-70. doi:10.12998/wjcc.v7.i2.156.
83 Aamann L, Dam G, Borre M, Drljevic-Nielsen A, Overgaard K, Andersen H, Vilstrup H,Aagaard NK. Resistance Training Increases Muscle Strength and Muscle Size in Patients With Liver Cirrhosis. Clin Gastroenterol Hepatol 2019; 18: 1179-87.e6. doi:10 .1016/j.cgh.2019.07.058.

84 Giallauria F, Cittadini A, Smart NA,Vigorito C. Resistance training and sarcopenia. Monaldi Arch Chest Dis 2016; 84: 738. doi:10.4081/monaldi. 2015.738.

85 Csapo R,Alegre LM. Effects of resistance training with moderate vs heavy loads on muscle mass and strength in the elderly: A meta-analysis. Scand J Med Sci Sports 2016; 26: 995-1006. doi:10.1111 /sms.12536.

86 Wackerhage H, Schoenfeld BJ, Hamilton DL, Lehti M,Hulmi JJ. Stimuli and sensors that initiate skeletal muscle hypertrophy following resistance exercise. J Appl Physiol (1985) 2019; 126: 30-43. doi:10.1152/japplphysiol.00685.2018.

87 Thompson PD, Arena R, Riebe D, Pescatello LS,American College of Sports M. ACSM's new preparticipation health screening recommendations from ACSM's guidelines for exercise testing and prescription, ninth edition. Curr Sports Med Rep 2013; 12: 215-7. doi:10.1249/JSR.0b013e31829 a68cf.

88 Wilkinson SB, Phillips SM, Atherton PJ, Patel R, Yarasheski KE, Tarnopolsky MA,Rennie MJ. Differential effects of resistance and endurance exercise in the fed state on signalling molecule phosphorylation and protein synthesis in human muscle. J Physiol 2008; 586: 3701-17. doi:10.1113/jphysiol.2008.153916.

Submitted: January 21, 2021

Revision received: February 7, 2021 Accepted for publication: February 7, 2021 